\title{
Website homes in on climate hazards
}

Is the average US citizen ready to pay $\$ 30$ to find out whether climate change will put their home at risk of being drowned by sea water, or burned in a wildfire?

David Purcell, a former banking executive, is betting that the answer is 'yes'. He has teamed up with climate scientists at the University of Arizona in Tucson and set up a website, called Climate Appraisal, that generates maps, graphs and commentary on environmental risks - including those related to climate change - for any location in the United States.

But some question whether, at this stage in the science, meaningful predictions on such a small scale can be made. "Ever since we knew about global warming, there's been a demand for bringing it down to a level that local people care about," says Gavin Schmidt, a climate modeller at NASA's Goddard Institute for Space Studies in New York, who hasn't seen Climate Appraisal's reports. "But there are some irreducible difficulties in doing so."

Purcell, who is based in Easton, Connecticut, says the website is a way to bring climate science to the public, and adds that his long-term goal is to direct at least $50 \%$ of the income it generates to climate research and education. He's built the site with the help of Jonathan Overpeck, a climate scientist at the University of Arizona and a lead author of the latest reports on climate change presented earlier this year by the Intergovernmental Panel on Climate Change (IPCC). "I saw that this could get people to take climate change seriously because they would see their stake in it," Overpeck says.

So far the undisclosed investment in Climate Appraisal has come from Purcell's pocket. Overpeck and two other Earth scientists at the University of Arizona have written articles for the site and advised on what data to present and how to present them for free. But Climate Appraisal has to strike a dif-

"Ever since we knew about global warming, there's been a demand for bringing it down to a level that local people care about." ficult balance in giving homeowners detailed information while not overstating the scientific certainty.

As the effects of global warming begin to be noticed, climate scientists have come under growing pressure to forecast what will happen on local scales of as little as a few kilometres. But most are wary of making statements about such impacts. It was only in its latest round of reports that the IPCC sought to do so - and it confined itself to producing forecasts for

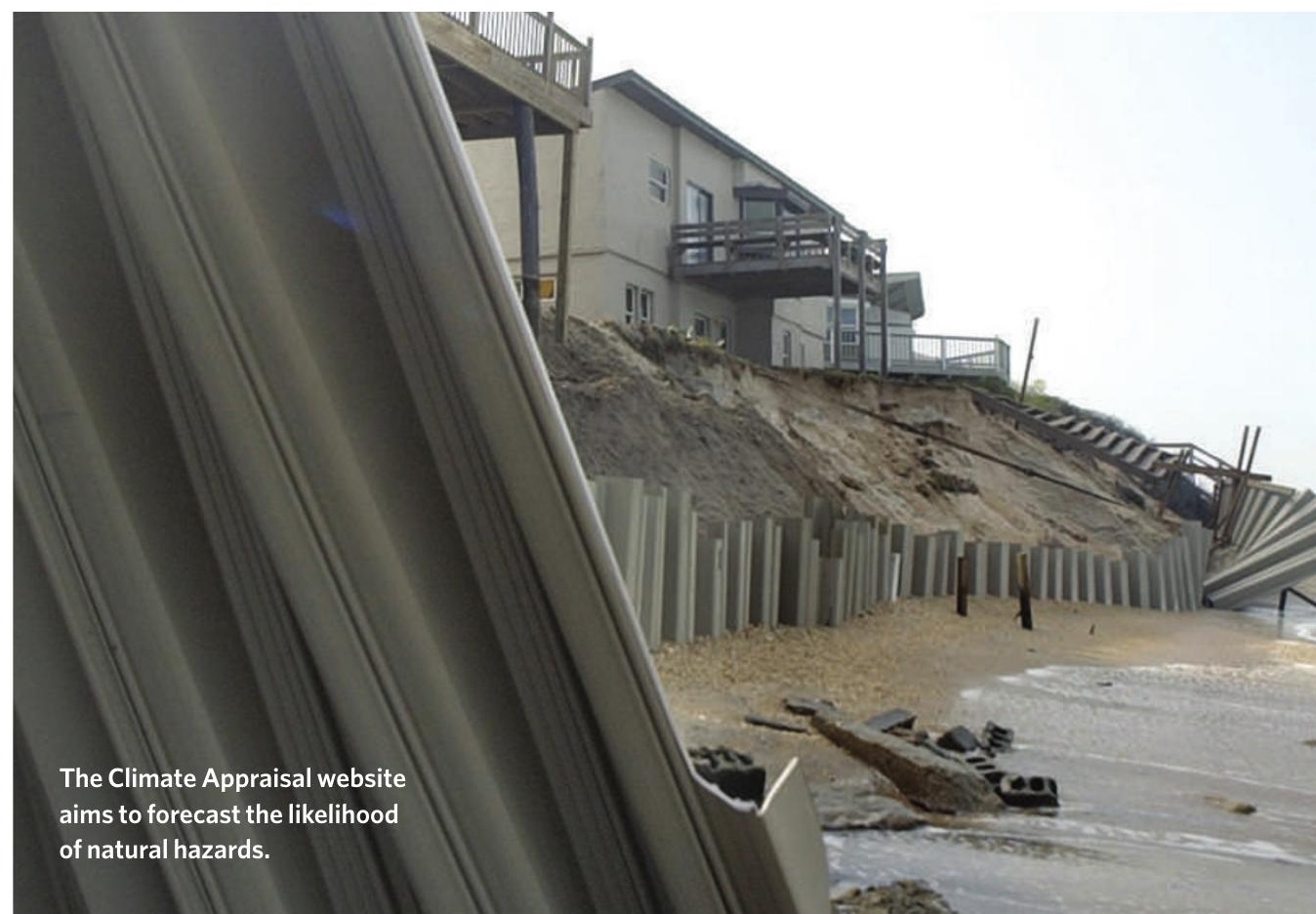

regions 500 kilometres across.

To evaluate Climate Appraisal's approach, Nature asked six climate scientists to comment on five of the website's reports for a range of US locations.

Most said that the site's biggest plus was the way it collates so many types of information. Providing historical data on extreme events such as floods, wildfires, hurricanes and tornadoes, plus lists of toxic-waste sites, data on air quality, and information about certain diseases, is helpful to people who want a broad idea of an area's hazards, they say.

But the information that the site presents on climate change is limited, our reviewers said, in large part because Overpeck and his colleagues have been careful not to go beyond what the science tells them.

Climate Appraisal's main address-specific data on climate change are projected temperatures for 2050 and 2100 and, for coastal addresses, sea-level changes for the coming century and beyond. For example, users can zoom in on an area just a few kilometres across to see whether it is likely to be submerged if the sea rose by about a metre.

Philip Mote, one of the reviewers and a climatologist at the University of Washington in
Seattle, says he would like to see more explanation and caveats given for both sea-level and temperature projections. In the case of sea-level rise, he says, although a metre rise is plausible within the next 100 years, complicating factors such as movement of Earth's continental plates make it difficult to predict how different shorelines will be affected.

"If I was doing this I would caveat it to death," says another reviewer, Linda Mearns, a climate scientist at the National Center for Atmospheric Research in Boulder, Colorado, and another lead author on the IPCC reports.

Overpeck recognizes that there are some gaps and glitches in the data, and is hoping that sales of the reports will allow him and his colleagues to replace some outmoded information with the latest IPCC forecasts and better models. For now, limited money and time mean using only the data that are "published, public and affordable". He says that the site's advice for users is as comprehensive as it needs to be, without being confusing. "If we included all the scientific discussion about all the uncertainties, no one would ever read it."

Purcell believes the site will give the public the kind of information that insurance companies are using to decide whether to cover certain risks. That's a live issue for many US homeowners: only last week, insurance company Allstate stopped offering policies to new 


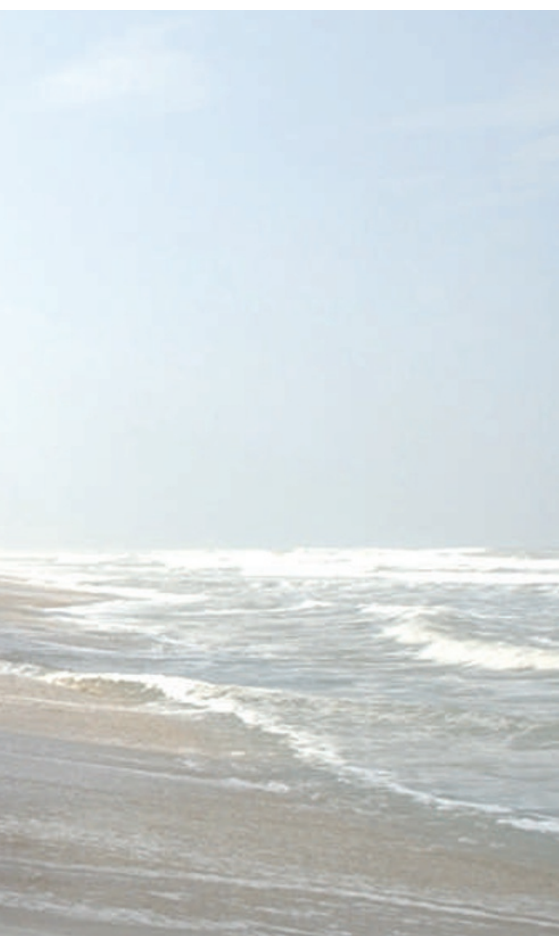

homeowners in California because of the growing risk of wildfires there.

With decades of experience in risk assessment, insurance companies and the consulting firms that they use remain best-placed to evaluate a place's environmental hazards, says Celine Herweijer, principal climate scientist for Risk Management Solutions in London. She adds that although the idea of giving the public risk information is a good one, the information Climate Appraisal is currently selling will be of limited use to the homeowner.

In the case of floods, for example, homeowners would benefit most from estimates of the probability of a flood of a certain depth, Herweijer says, rather than from a national map of flood events, or a list of past floods in their area.

By linking climate change to someone's home address, Climate Appraisal is entering new and fairly treacherous waters. All in all, however, Herweijer and other climate scientists say the idea of making local risk information more widely available is valuable. In attempting to work out what to present and how to present it, most agree that the venture should be admired for its ambition. "You have to applaud it for what it is trying to do," says Schmidt.

Lucy Odling-Smee

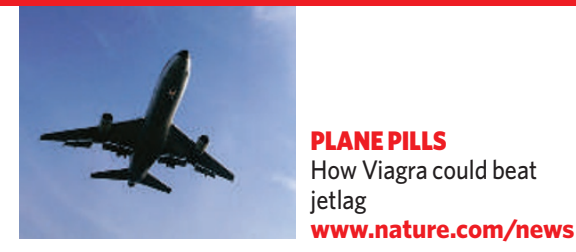

\section{Help flies in for human genome}

Worms and flies are to be enlisted by researchers attempting to make sense of the instructions embedded in the human genome.

Since 2003, geneticists in the United States have been engaged in the pilot phase of a project called ENCODE - the Encyclopedia of DNA elements - which aims to catalogue all the functional parts of the human genome at a cost of around US $\$ 20$ million a year.

Now, a four-year, $\$ 57$ million project called modENCODE will add roundworms (Caenorhabditis elegans) and fruitflies (Drosophila melanogaster) to the mix. By analysing these trusty model organisms, scientists hope to make better sense of the human-genome data gleaned from ENCODE.

Grants from modENCODE will support scientists who are cataloguing the major types of functional genetic elements. These include RNAs that cut genetic transcripts into different genes and fine-tune gene expression, modifications to bundles of protein and DNA called chromatin, and DNA sequences that control how and when genes are transcribed.

Researchers say that the

Analysing the fruitfly could help researchers uncover the secrets of the human genome.

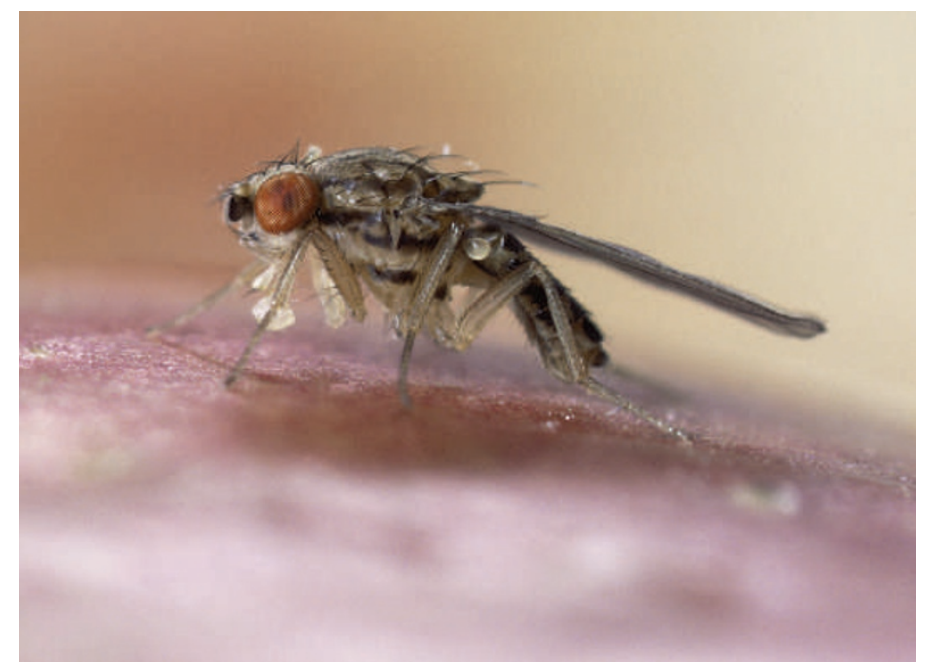

project, which was announced by the US National Human Genome Research Institute (NHGRI) on 14 May, is needed because ENCODE has shown that the human genome is even more complex than they originally thought (see Nature 441, 398-401; 2006).

ENCODE's pilot phase genome and has generated a slew of techniques for analysing a portfolio of technologies that can be applied with high specificity and sensitivity to decode the parts list of the human genome at a rather precise level," says Francis Collins, the NHGRI's director.

So far, the project has revealed that genes are regulated by complicated networks that span huge portions of the genome; that RNA plays a previously unappreciated part in determining how proteins are made from genes; and that scientists don't fully understand some of the regulatory motifs that they have been studying for years.

Scientists hope that modENCODE will enable them to work out these processes by looking at the model covered just $1 \%$ of the human the genome. "We now have organisms, which have much smaller genomes than humans and are easier to manipulate in the lab. The roundworm has about 100 million base pairs in its genome and the fruitfly 180 million, compared with 3 billion base pairs found in the human genome.

"These are hard issues, and without the experimental feedback you can get from worms and flies, it's hard to see when we're really going to touch ground," says Robert Waterston of the University of Washington in Seattle and recipient of a \$5.4-million modENCODE grant to study C. elegans.

But at the end of modENCODE's first four years, will scientists be able to pat themselves on the back and move on to something else? It's unlikely, they say, given that human genetics seems to evolve into a more complicated subject with every new foray into the genome.

"We should get a lot closer," says Lincoln Stein of Cold Spring Harbor Laboratory in New York, and the head of a new centre to coordinate the modENCODE data. "If we can't nail it down, we'll at least have a lot of it thumbtacked to the wall." Erika Check 